\title{
Perceptions of ORganisational COMMITMENT, JOB SATISFACTION AND TURNOVER INTENTIONS IN A POST-MERger SOUTH AfricAN TERTIARY INSTITUTION
}

\author{
ADAM MARTIN \\ GERT ROODT \\ Department of Human Resource Management \\ University of Johannesburg \\ South Africa \\ Contact person: Adam Martin \\ e-mail: jawbax@gmail.com
}

\begin{abstract}
A merger can be considered both a phenomenological and significant life event for an organisation and its employees, and how people cope with and respond to a merger has a direct impact on the institutional performance in the short to medium term. It is within this context that post-merger perceptions of a tertiary institution were investigated. A predictive model (determined the "best" of 15 predefined models) of turnover intentions was developed for employees of a South African tertiary institution (having undergone its own recent merging process). A systematic model-building process was carried out incorporating various techniques, among others structural equation modelling and step-wise linear regression. The final predictive model explained $47 \%$ of the variance in turnover intentions. Contrary to expectations, commitment does not correlate more strongly than satisfaction does with turnover intentions.
\end{abstract}

Keywords: merger, transformation, environment, restructuring, workplace

Restructuring in any organisation is characterised by uncertainty, high levels of anxiety, low levels of morale and tardy job performance, as well as high levels of absenteeism and staff turnover, all of which potentially impact on productivity and performance. The transition from the old structure to the new can be a time of hope and exhilaration on the one hand, yet a time of uncertainty, risk and loss on the other (Gersick, 1991).

Fourie(1999) states that theglobal phenomenon of transformation of higher education, taking place in most countries in the world, is an undeniable fact. Green and Hayward $(1997$, p. 3) argue that "(a)lthough higher education is often seen as slow to change or downright resistant, it has undergone rapid transformation throughout the world in the last 25 years and may be in a period of unprecedented change".

The abolition of apartheid and the post-1994 aftermath period have seen South Africa undergoing tremendous transformation in its political, economic, social and technological environments (Bainbridge, 1996). As part of the social environment, education, too, is destined for the restructuring and transition characterising the country and its people. Mergers are taking place between teacher training colleges and technical colleges, as well as between universities and technikons. In South Africa to date, the politically inspired mergers (see Higher Education Act 101 of 1997 (South Africa, 1997); National Plan for Higher Education (Ministry of Education, 2001)) have been limited mainly to the federal absorption of smaller, specialist institutions into universities. However, larger and more unitary mergers have been advocated in order to address two particular problems of the apartheid legacy - the disadvantages experienced by historically black universities in the form of declining enrolments and bankruptcies ${ }^{1}$; and the staff profiles of the former traditionally white Afrikaans universities which still do not closely reflect racial distribution (Reddy, 1998).

Few researchers have investigated the commitment perceptions of the employees (and the associated work constructs) who feel the full impact of these restructurings in a South African context. This subsequently results in a dearth of knowledge on the context of South African mergers and acquisitions of tertiary institutions. Arnolds and Boshoff (2004, p. 2) validly point out that the human capital element in the form of teacher/ facilitator/lecturer in educational institutions (knowledgeintensive organisations) is far more important than in other organisations, "as the development, transfer and reception of knowledge cannot be achieved without the inputs of the educators". In light of the recent restructuring of the institution in question, no attempt has yet been made to gauge the levels of organisational commitment among its employees. It is within this context that the research problem emerges: What are the employee perceptions of job satisfaction, organisational commitment and turnover intentions in a post-merger tertiary institution and how are these variables related?

\section{Job satisfaction}

Job satisfaction is a frequently studied variable in organisational behaviour research, and also a central variable in both research and theory of organisational phenomena. What is agreed is that, stemming from cognitive processes, job satisfaction is a generalised affective work orientation towards one's present job and employer (Lincoln \& Kalleberg, 1990).

Leading theorists such as Maslow $(1943 ; 1954)$ and Herzberg and Mausner (1959) have emphasised the importance of the fulfilment of various needs of employees, which will determine their behaviour in organisations.

Maslow (1943) postulated a hierarchy ranging from lower to higher order needs. Lower order needs, such as survival needs, are often referred to as extrinsic needs (e.g. compensation and working conditions), while higher order needs are referred to as intrinsic needs (e.g. recognition and achievement). Herzberg and Mausner (1959) formulated the two-factor theory of job satisfaction and postulated that satisfaction and dissatisfaction 
were two separate and sometimes unrelated phenomena. Extrinsic factors were named 'hygiene' factors and were claimed to involve primarily the context in which the job was performed. Intrinsic factors were named 'motivators' and were believed to involve mainly aspects of the job itself

Of particular relevance to this study was the utilisation of the intrinsic-extrinsic definition of job satisfaction used by Weiss, Dawis, England and Lofquist (1967): Intrinsic satisfaction was derived from performing the work and consequently experiencing feelings of accomplishment, self-actualisation and identity with the task. Extrinsic satisfaction was derived from the rewards bestowed upon an individual by peers, supervisors or the organisation, and can take the form of recognition, compensation and advancement. This stems from the assumption that each person seeks to achieve and maintain correspondence with his or her environment. Furthermore, this association with the environment at work can be described in terms of the work environment fulfilling the requirements of the individual (satisfaction) and the individual fulfilling the requirements of this environment (satisfactoriness) (Cook, Hepworth, Wall \& Warr, 1981)

Many researchers have opted for different methods of measuring job satisfaction. Locke (1976) explains that for researchers to understand job attitudes, they need to understand job dimensions, which are complex and interrelated in nature. He mentioned common dimensions of job satisfaction such as work, pay and promotions. Spector (1997) adopted a multifaceted approach to job satisfaction, including facets such as appreciation, communication and fringe benefits. One model of particular interest was the Price-Mueller model (Price \& Mueller, 1981), which assumed that employees value certain conditions of work and if these conditions are found in the workplace, employees will be more satisfied and committed and less likely to leave the organisation.

For purposes of this study, job satisfaction was defined as a pleasurable or positive emotional state that results from the appraisal of one's job or job experiences (Locke, 1976, p. 1300).

Many investigations have been done over the past four decades, with contradictory results, which have left the true nature of the relationship between age and job satisfaction unresolved; still, age may be a contributing factor in the experience of job satisfaction. Empirical research endeavours have found a U-shaped relationship (Clark, Oswald \& Warr, 1996). A positive linear relationship has also been found between employee age and job satisfaction and in this case the employees became more satisfied with their job as their chronological age progressed (as mentioned in Herrera, 2003; Ingersoll, Olsan, Drew-Cates, De Vinney \& Davies, 2002; Oswald \& Gardner, 2001; and Shields \& Ward, 2001). A negative linear relationship between age and job satisfaction has also been found by Muchinsky (1978), while an inverted U-shaped or inverted J-shaped relationship was found by Oswald (2002). Cases of no significant relationship have also been observed (Chambers, 1999).

Job satisfaction was seen to follow a U-shaped relationship with respect to tenure in current position (Shields \& Ward, 2001), while no relationship has also been indicated with years of experience (such as Bedeian, Farris \& Kacmar, 1992; Bertz \& Judge, 1994; and Ma, Samuels \& Alexander, 2003). However research has also shown that overall job satisfaction increased as the years of experience increased (Chambers, 1999; Herrera, 2003).

A number of empirical studies have found female workers to have lower levels of job satisfaction than their male counterparts, as it was argued that male officials dominate most of the public organisations (Bedeian et al., 1992; Herrera, 2003). Other studies found that gender did not feature significantly in terms of overall job satisfaction scores (examples are Brush, Moch \& Pooyan, 1987; Cano \& Miller, 1992; and Witt \& Nye, 1992).

A meta-analysis of 21 studies reported no racial differences (Brush et al., 1987), while a recent study found that Asian and black people reported lower overall job satisfaction than the omitted category of white people (Greenhaus, Parasuraman \& Wormley, 1990; and Tuch \& Martin, 1991). Another study, however, indicated that black people reported higher job satisfaction levels than white people (Vallabh \& Donald, 2001).

\section{Organisational commitment}

Organisational commitment has a long history, and has been the subject of a great deal of research and empirical attention both as a consequence and an antecedent of other work-related variables of interest. Commitment has evolved as a wide range of 'types' (e.g. engagement, attachment, commitment, involvement) within a wide spectrum of foci (e.g. work, job, career, profession/ occupation, organisation, union), while studies on commitmen varied between the categories of behavioural, attitudinal and motivational within three broad research streams through sociological, industrial/organisational psychology and health psychology (Roodt, 2004a). Despite the lack of consensus on the various definitions, conceptualisations and measurements, a common theme is shared across all these deviations, namely that organisational commitment is considered to be a bond or linkage of the individual to the organisation.

Morrow (1983) highlighted that growth in the commitmentrelated concepts has not been accompanied by careful segmentation of commitment's theoretical domain in terms of the intended meaning of each concept or the concepts' relations among themselves. Roodt (2004a) subsequently realised that research was characterised by concept redundancy and concept contamination. Concept redundancy was defined in this context as the use of related variables that largely overlap in meaning, e.g. work involvement and work commitment. Concept contamination occurs when a variable contains a large proportion of shared or common content with other 'unrelated' variables, e.g. morale and work involvement (Roodt, 2004a).

Organisational commitment, in this study, is viewed as a unidimensional construct. This stems from Roodt's (1997) proposal of a unidimensional way of measuring commitment by distinguishing between different commitment foci. Furthermore, Roodt (1997) concludes that a distinction between different work-related foci is only of theoretical importance if the same theoretical base is used in operationalising the different foci. Thus, the question needs to be seriously posed as to whether any purpose is served by distinguishing between the different work-related foci, except maybe to obtain a better understanding of the dynamics of organisational commitment or the relative importance of each foci. This was supported, among others, by Shore, Newton and Thornton (1990), as they advocated that these attitudes should be related due to their focus being the same.

It seems as if the golden thread running through all the definitions of commitment is the potential for a particular focus to satisfy salient needs. A motivational approach (as opposed to the attitudinal and behavioural approaches), which also includes the realisation of salient values and the achievement of salient goals, as suggested by Roodt (2004a), seems to be more appropriate to the study of commitment. This approach only focuses on the state of commitment (cognitive predisposition) in a particular focus. The state of commitment is not only separated from its antecedent and consequential conditions and behaviours, but also from its related affective and conative components that are also present in other widely used constructs, such as job satisfaction and turnover intentions respectively. 
For the purpose of this study, organisational commitment can therefore be defined as a cognitive predisposition towards a particular focus, insofar as this focus has the potential to satisfy needs, realise values and achieve goals (Roodt, 2004a, p. 85).

There are contradictory findings in the relevant literature about the relationship between age and commitment. While some studies have found no relationship between age and commitment (Knoop, 1986; Müller \& Roodt, 1998), others have found that commitment has been positively related to age (including Cohen \& Lowenberg, 1990; Ingersoll et al., 2002; Lok \& Crawford, 1999; and Mathieu \& Zajac, 1990).

There has been support of a positive relationship with tenure and affective and continuance commitment (Hackett, Bycio \& Hausdorf, 1994). Other studies have found that the longer employees worked in an organisation, the higher their levels of commitment (Cohen \& Lowenberg, 1990). However, no meaningful relationship was found between tenure and organisational commitment (including Lok \& Crawford, 1999; McFarlin \& Sweeney, 1992; Reilly \& Orsak, 1991; and Roodt, 992).

Conflicting results are also present with gender. Some studies that were conducted on gender found women to be more committed than men (Mathieu \& Zajac, 1990), while others found that men are more committed to the organisation than their female colleagues (Cohen \& Lowenberg, 1990). Other researchers found that gender was not related at all to commitment (examples are Aven, Parker \& McEvoy, 1993; Kacmar \& Carlson, 1999; and McFarlin \& Sweeney, 1992).

Regarding race: White people have reported higher levels of commitment than their black counterparts (Vallabh \& Donald, 2001).

\section{Turnover behaviour}

Turnover behaviour is a multistage process that includes attitudinal, decisional and behavioural components. The theory of planned behaviour (Ajzen, 1991) suggests that behavioural intention is a good predictor of actual behaviour. Studies (such as that of Fox \& Fallon, 2003; Hom \& Hulin, 1981; Mobley, 1982; Mobley, Horner \& Hollingsworth, 1978; Newman, 1974; Shields \& Ward, 2001; and Tett \& Meyer, 1993) have successfully demonstrated that behavioural turnover intentions are consistently seen with moderate to strong correlations with turnover, substantiating the notion of Ajzen (1991). There is considerable support for the notion that intention to quit-stay is probably the most important and immediate individual-level antecedent and predictor of turnover decisions (as seen in the work of Chiu \& Francesco, 2003; Fox \& Fallon, 2003; Mobley, 1982; Slate \& Vogel, 1997; Steel \& Ovalle, 1984; and Tett \& Meyer, 1993)

As indicated above, the immediate precursor of behaviour is thought to be intentions, and therefore the best predictor of turnover should be intention to turnover. However, Mobley (1977) has suggested that there are several other possible turnover cognition types of interest to add in the withdrawal decision (the decision to quit a job), highlighting notions such as thinking of quitting, followed by the intention to search for alternatives.

Furthermore, many studies have been based on the belief that turnover is an individual choice behavioural pattern based on the conceptualisation that it is a psychological response (Lum, Kervin, Clark, Reid \& Sirola, 1998; Mobley, Griffeth, Hand \& Meglino, 1979).

For the sake of this study, turnover intentions are seen as a mental decision (conation) intervening between an individual's attitudes (affect) regarding a job and his/her subsequent behaviour to either stay or leave (Sager, Griffeth \& Hom, 1998, p. 255).

Research results dealing with the relationship with age are seemingly consistent. Results continually indicate that the younger the age at application to the organisation, the higher the turnover association (Chiu \& Francesco, 2003; Jacobs, 2005). It has been reported (Hellriegel \& White, 1973), however, that no consistent statistical differences were found, as observed by Yin and Yang (2002) in a recent meta-analysis.

Conflicting results merge in terms of tenure. Studies support the finding of a statistically significant positive correlation between tenure and turnover intentions (Jacobs, 2005; Lum et al., 1998); while significant negative correlations have also been encountered (Chiu \& Francesco, 2003).

Many studies have reported that no significant relationship exists between gender and turnover intentions (such as Lambert et al., 2001; Lum et al., 1998). This was also the case found in a longitudinal study (Porter, Steers, Mowday \& Boulian, 1974). Another study, however, reported a negative correlation whereby women had higher turnover intentions (Marsh \& Mannari, 1977).

Race has been indicated as a poor and inconsistent variable when used as a predictor of turnover (Lambert et al., 2001), but recently it was found that African professional nurses are significantly more inclined to quit than their coloured or white counterparts (Jacobs, 2005). It has also been found that far more black managers were seriously considering leaving their current positions than their white counterparts (Vallabh \& Donald, 2001)

\section{The relation between job satisfaction, organisational com-} mitment and turnover intentions

Numerous studies have continually shown the effect of both job satisfaction and organisational commitment on turnover intentions. Organisational commitment and job satisfaction are viewed as an essential component of turnover models because their empirical relationship with voluntary turnover has been established through numerous meta-analyses, in which a negative relationship with turnover intentions has continually been illustrated (Cohen, 1993; Lee, Carswell \& Allen, 2000; Mathieu \& Zajac, 1990; Meyer, Stanley, Herscovitch \& Topolnytsky, 2002; Steel \& Ovalle, 1984; Tett \& Meyer, 1993; and Yin \& Yang, 2002). The greater the job satisfaction, the less the likelihood that the individual will leave the organisation, and, the higher the commitment levels of the employee, the lower the predicted turnover intentions. Organisational commitment and job satisfaction were proved to correlate with one another yielding a positive association. The purpose of this article is to investigate this relationship more closely in a post-merger institution.

A growing body of literature indicates that the turbulence caused by mergers and acquisitions can be a traumatic event in the lives of individuals (Morrison \& Robinson, 1997) and organisations (Ashkenas \& Francis, 2000; Lubatkin, 1983). Several studies have shown that employees' organisational commitment, job satisfaction and turnover intentions have been negatively affected as a result of a merger or an acquisition or even the announcement of one (Armstrong-Stassen, Cameron, Mantler \& Horsburgh, 2001; Bastien, 1987; Buono, Bowditch \& Lewis, 1985; Covin, Sightler, Kolenko \& Tudor, 1996; Davy, Kinicki, Kilroy \& Scheck, 1988; Jones, 2000; Weber, Lubatkin \& Schweiger, 1994; and Zhu, May \& Rosenfield, 2004), which can be very costly to firms.

From the above there seems to be a consensus as to the outcomes of a merger or amalgamation and, focusing on the primary 
constructs in question, all are negatively affected by such a process. Job satisfaction is reduced; organisational commitmen is lowered; and turnover intentions levels are increased. There has been indication that knowledge of relationships between mentioned constructs and the causes thereof is still lacking (Armstrong-Stassen et al., 2001; Cartwright \& Cooper, 1990; Jones, 2000; Singh, 1999). This is generally more the case on the South African front where research in this context is meagre, save for that of Jansen (2002) and Arnolds and Boshoff (2004).

\section{RESEARCH DESIGN}

\section{Research approach}

The research approach can be described as a non-experimental and cross-sectional field survey, the data as primary data, and data analysis as ex-post facto and correlational. The completion of the electronic questionnaires was personally administered and anonymously handled. The medium used was the internet, which provides the opportunity to conduct surveys more efficiently and effectively than the traditional means. The primary reason for the utilisation of the internet was due to cost saving and the geographic location of all campuses.

\section{Research method}

Sample

The non-probability (convenience) sample consisted of 367 employees of a South African tertiary instituition, yielding a response rate of $16 \%$. The target population can be described as all academic/research, support and administrative personnel ( $n=2$ 279) of the recently merged tertiary institution (i.e. all white-collar workers) irrespective of their current employment contract (i.e. permanent, contract or temporary). The unit of analysis is each employee regardless of their status within the respective departments and across all the relevant campuses. This enabled the researcher to achieve a diverse offering in terms of the employees of the institution.

\section{Measuring instruments}

Three instruments were used to measure the variables in this study, namely the Minnesota Satisfaction Questionnaire, the Organisational Commitment Questionnaire and the Turnover Intentions Questionnaire.

\section{Minnesota Satisfaction Questionnaire (MSQ)}

The Minnesota Satisfaction Questionnaire (MSQ) (Weiss et al., 1967) assessed the level of job satisfaction among the employees. The MSQ is designed to measure an employee's satisfaction with his/her job. It provides more specific information on the aspects of a job that an individual finds rewarding, than do more general measures of job satisfaction. The short form of the MSQ was used, namely the MSQ20. This form consists of 20 items from the long form MSQ (consisting of 100 items) that best represent each of the 20 scales. The purpose of the MSQ20 is therefore to determine the degree of job satisfaction in characteristics associated with the task itself (intrinsic satisfaction), in nontask characteristics of the job (extrinsic satisfaction) and in overall job satisfaction (total satisfaction) (Weiss et al., 1967). Spector (1997) commented that most researchers who use the short form combine all the items into a single total score, or compute extrinsic and intrinsic satisfaction subscales from the subsets of items. The questionnaire was modified in this study to modernise the phrasing of questions to be more closely related to the respondents.

\section{Organisational Commitment Questionnaire (OCQ)}

A motivational approach was adopted to study commitment within this context (as discussed above, the other relatively well-known approaches are attitudinal and behavioural). This entails needs, values and goals that can all be regarded as motivational constructs (Roodt, 2004a). The Organisational
Commitment Questionnaire (OCQ) developed by Roodt (1997) was therefore used to measure organisational commitment. Furthermore, this questionnaire was selected due to the predictive model of turnover intentions in this study, as it is based on the assumption that university employees who satisfy their higher order needs (measured through job satisfaction) will be inclined to stay in their jobs. The original questionnaire was modified from 38 items to 18 . The reduction came as a result of selecting those items of the original 38 that illustrated the highest metric item total correlation per each section from Roodt's original 1997 study. The foci of the questionnaire consist of work, job, career, occupation and organisation, i.e. all organisationally related, as no distinction between these foci need be made (Roodt 1997, 2004a).

\section{Turnover Intentions Questionnaire}

The measure of turnover intentions was addressed by an unpublished questionnaire developed by Roodt (2004b). Although turnover intentions are thoroughly covered in the literature, there is still a need to validate scales formally to represent turnover cognitions (Sager et al., 1998). The motivation for using this questionnaire is that most instruments in the literature measure turnover intentions on only a relatively small number of items. Various researchers have applied a single item scale (Guimaraes, 1997; Lambert, Hogan \& Barton, 2001) with obvious metric limitations, while a few other studies have used more than three items per instrument (Becker, 1992; Fox \& Fallon, 2003; Lum, et al., 1998). The questionnaire is made up of 15 items that are measured on a five-point intensity response scale anchored at the polar ends.

\section{Research procedure}

Permission to conduct the research in the institution was first obtained from the deputy vice-chancellor concerned. Hereafter an invitation was sent out via e-mail to the 2279 potential participants requesting their participation in the electronic survey. An electronic link was provided in the invitation letter that directed potential respondents to the survey instrument. It took between 20 to 30 minutes to complete the survey and all responses were submitted anonymously.

\section{Statistical analysis}

Each questionnaire was factor analysed in line with the rules stipulated by Hair, Black, Babin, Anderson and Tatham (2006) in order to determine the factor structure of the instruments. This procedure includes first- and second-level factor analysis and was followed by a reliablity analysis.

The analyses followed a two-phase procedure. The first phase of the analysis comprises the initial diagnostic testing whereby statistical reliability and validity are determined. In this, results of the descriptives, factor analyses (both first and second levels), reliability analyses (iterative item analyses) and normality were addressed. The main focus of the first phase of the data analysis is to provide proof that the measuring instruments and variables were reliable and valid for the purpose of the study.

In the second phase, the results will be described by referring to the objectives of the study, namely to end with a best-fitting predictive model incorporating significant demographic variables. This will be addressed by means of the process of inferential testing (Analysis of Variance (ANOVA) and t-tests), correlations, Structural Equation Modelling (SEM), two-way ANOVA and finally, a step-wise linear regression. The focus of the second phase is to investigate the relationships between sets of key variables in the initial 15 predefined theoretical models in order to present the most parsimonious predictive model of the selected dependent variable attained from the SEM.

Given the potential diversity of the respondents represented and the different campuses participating in the study, it is worthwhile considering the possibility of bias manifesting 
in the sample. Consequently, the generalisations made from the research propositions should be treated with caution. A bias analysis (where data was possible) was carried out on the background variables to determine what sections of the population were misrepresented. Table 1 represents the outcome of the analysis.

Based on the above results, the sample data assimilated is only a representation of the population in terms of the age and conditions of service. This is considered a limitation of the study and was noted and acknowledged accordingly.

\section{RESULTS}

Only results of interest will be highlighted. Factor analysis was incorporated to assist in establishing the reliability and validity (namely construct and convergent validity) of the measuring instruments used in the study. The procedure assisted in improving on the already established instruments catering for the sample at hand. Both first- and second-level factor analyses were carried out in which all first-order factor analyses yielded one second-order factor. The results of the attained reliabilities and intercorrelation of the finalised work constructs (secondorder factors) of the different instruments are depicted below.

A substantial correlation was found between Turnover Intentions and Job Satisfaction. All selected procedures assume normality is present and hence the need to test it accordingly. The results of the Kolmogorov-Smirnov test used indicated that all three attained variables are considered to follow a normal distribution

These tests were utilised to determine whether any of the background variables specified has a statistical relationship with the work constructs in the laid out research objectives. All results (and their respective coefficient of associations) are depicted in Table 3 with statistically significant relationships indicated accordingly. The researcher used measures of association to ascertain the practical significance of the contextual factors with the independent variables as per the questionnaires. According to Rosenthal, Rosnow and Rubin (2000), an Eta value of less than $0.1(0.0-0.09)$ indicates that the independent variable had a negligible effect on the construct in question. An Eta value of $0.1-0.29$ shows a small effect size, $0.3-0.49$ a medium effect size, and values above 0.50 a large effect size.

TABLE 1

Bias analysi

\begin{tabular}{ll}
\hline VARIABLE & p-VALUE \\
\hline Age & 0.141 \\
Gender & 0.000 \\
Race & 0.000 \\
Home Language & 0.000 \\
Marital Status & 0.047 \\
Campus & 0.000 \\
Conditions of Service & 0.059 \\
\hline
\end{tabular}

TABLE 2

Means, reliabilities and intercorrelations

\begin{tabular}{|c|c|c|c|c|c|c|}
\hline INSTRUMENT & $\mu$ & $\mathrm{SD}^{1}$ & $\alpha$ & JS & OC & TI \\
\hline Job Satisfaction & 3.321 & 0.713 & 0.898 & & 0.408 & -0.689 \\
\hline $\begin{array}{l}\text { Organisational } \\
\text { Commitment }\end{array}$ & 4.026 & 0.563 & 0.888 & 0.408 & & -0.396 \\
\hline $\begin{array}{l}\text { Turnover } \\
\text { Intentions }\end{array}$ & 2.831 & 0.872 & 0.895 & -0.689 & -0.396 & \\
\hline
\end{tabular}

Correlations all significant at the 0.01 level.

${ }^{1}$ SD denotes Standard Deviation
TABLE 3

Summary of testing between background variables and instruments

\begin{tabular}{clll}
\hline INSTRUMENT & VARIABLE & $\boldsymbol{p}$-VALUE & Eta \\
\hline \multirow{2}{*}{ Job Satisfaction } & Age & 0.297 & 0.140 \\
& Gender & 0.711 & 0.021 \\
& Race & 0.095 & 0.103 \\
& Marital Status & 0.938 & 0.004 \\
& Education & 0.774 & 0.090 \\
& Tenure & 0.173 & 0.106 \\
\hline Organisational Commitment & Age & 0.008 & 0.226 \\
& Gender & 0.070 & 0.105 \\
& Race & 0.001 & 0.196 \\
& Marital Status & 0.426 & 0.046 \\
& Education & 0.006 & 0.233 \\
& Tenure & 0.595 & 0.059 \\
\hline \multirow{2}{*}{ Turnover Intentions } & Age & 0.030 & 0.201 \\
& Gender & 0.784 & 0.016 \\
& Race & 0.581 & 0.032 \\
& Marital Status & 0.182 & 0.077 \\
& Education & 0.262 & 0.147 \\
& Tenure & 0.005 & 0.184 \\
\hline
\end{tabular}

As seen from the above, all highlighted Eta values are indicative of small measures of association (ranged between 0.1 and 0.29).

The SEM technique was utilised to attain a best fitting model between all considered work constructs. In this analysis, SEM was utilised to determine firstly which of the 15 hypothesised models held statistically and secondly which model was the best fitting, and thereafter which model's dependent variable has the largest amount of variance explained ${ }^{2}$. The results indicated that models proved the strongest with Turnover Intentions determined as the dependent variable. This was due to the most variance being explained in the prediction of Turnover Intentions with a value of 55.4\% (Models 7, 10 and 12). This is closely followed by Job Satisfaction with the highest value being that of $55 \%$. However, Organisational Commitment yielded low levels of variance, as compared to the other work constructs, explained with the highest value being that of $16.6 \%$. Three models of Turnover Intentions resulted from this procedure and are depicted in Figure 1.

Hair et al. (2006) contend that, as a guideline for establishing whether a fit is acceptable or unacceptable, multiple indices need be reported. Table 4 presents the respective fit indices of the three abovementioned models.

Due to space restriction, the following abbreviations will be used in the table:

- $\mathrm{X}^{2}=$ Relative Chi-Square Measurement $\left(\mathrm{X}^{2} / \mathrm{df}\right)$

- $\mathrm{CFI}=$ Comparative Fit Index

- GFI = Goodness-of-fit Index

- RMSEA = Root Mean Square Error of Approximation

- $\mathrm{TI}=$ Turnover Intentions

The above summary shows that the Relative Chi-Square Measurement has an acceptable fit as it falls under the ratio of 5 to 1 (SPSS Inc, 2005). The Root Mean Square Error of Approximation is within reason, as it falls just outside the preferable level of 0.08, as Naudé and Rothman (2004) recommend that acceptable levels of the RMSEA should be 0.05 or less and should not exceed

TABLE 4

Structural equation modelling outcome summary

\begin{tabular}{llllll}
\hline MODEL & $\mathrm{X}^{2}$ & CFI & GFI & RMSEA & TI \\
\hline$\# 7$ & 3.591 & 0.670 & 0.662 & 0.089 & 0.554 \\
$\# 10$ & 3.591 & 0.670 & 0.662 & 0.089 & 0.554 \\
$\# 12$ & 3.591 & 0.670 & 0.662 & 0.089 & 0.554 \\
\hline
\end{tabular}




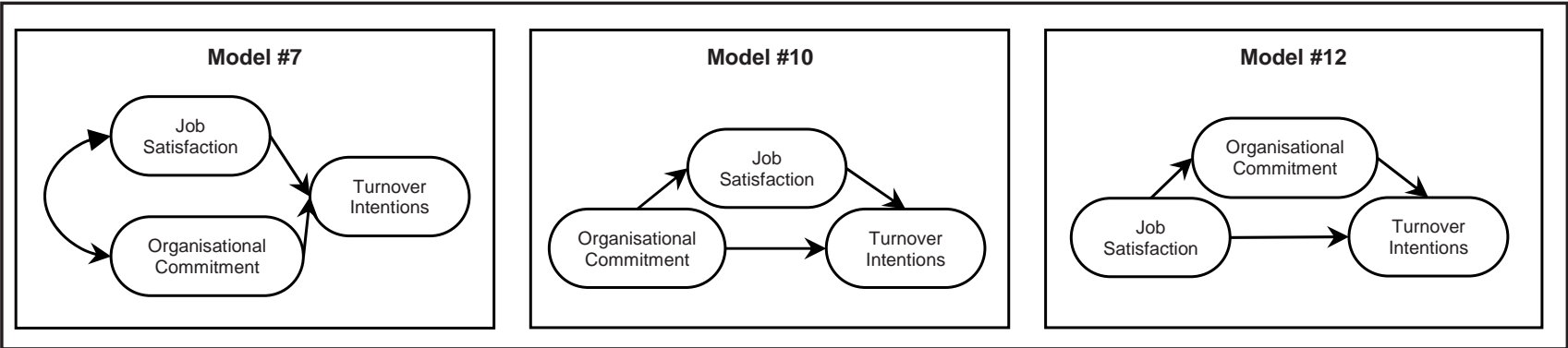

FIGURE 1

Selected hypothesised models

0.08. However, both the Comparative Fit Index and Goodnessof-fit Index yielded poor fits, with their respective values lying between 0.67 and 0.66 , which is lower than the acceptable level of 0.9 (Naudé \& Rothman, 2004).

The two-way ANOVA allowed the researcher to examine the effects of two independent variables whereby the only concern of this procedure is to identify interaction effects between the independent variables in predicting the dependent variable, namely in this case Turnover Intentions. Summarised in Table 5 are the outcomes of all interactions with Turnover Intentions (with respective $\mathrm{p}$ values and measure of associations).

The result yielded only one interaction of interest, which was that between race and gender, with a small effect size.

The final procedure of step-wise linear regression determined the best fitting model, incorporating both the work constructs selected and the relevant demographic variables that have loaded significantly on the dependent variable. Here all independent variables, namely the form the work constructs adopt (suggested by the SEM), the individual contribution from each demographic variable (suggested by the ANOVA and t-tests) and the interaction from the demographic variables (suggested by the two-way ANOVA), were regressed on the dependent variable Turnover Intentions.

A comparison of each model (7, 10 and 12) is depicted in Table 6.

TABLE 5

Summary of two-way ANOVA testing

\begin{tabular}{lll}
\hline INTERACTION & P-VALUE & ETA \\
\hline Age / Gender & 0.664 & 0.107 \\
Age / Race & 0.442 & 0.129 \\
Age / Marital Status & 0.840 & 0.084 \\
Age / Education & 0.678 & 0.217 \\
Age / Tenure & 0.050 & 0.238 \\
Gender / Race & 0.049 & 0.116 \\
Gender / Marital Status & 0.640 & 0.027 \\
Gender / Education & 0.605 & 0.111 \\
Gender / Tenure & 0.200 & 0.104 \\
Race / Marital Status & 0.284 & 0.063 \\
Race / Education & 0.331 & 0.142 \\
Race / Tenure & 0.173 & 0.110 \\
Marital Status / Education & 0.340 & 0.139 \\
Marital Status / Tenure & 0.662 & 0.053 \\
Education / Tenure & 0.094 & 0.234 \\
\hline
\end{tabular}

TABLE 6

Comparison of the models

\begin{tabular}{lll}
\hline MODEL & NUMBER OF VARIABLES ENTERED & $\begin{array}{l}\text { ADJUSTED } \\
\text { R SQUARE }\end{array}$ \\
\hline$\# 7$ & Two & 0.445 \\
$\# 10$ & Three & 0.470 \\
$\# 12$ & Three & 0.466 \\
\hline
\end{tabular}

Model comparison was determined through the comparison of the Adjusted R-Square. Thus, Model 10 was selected as the final model consisting of the predicted Turnover Intentions, being significantly predicted by Job Satisfaction, Tenure, and a combination of Job Satisfaction and Organisational Commitment.

The final equation achieved in the prediction of Turnover Intentions can be represented below. Turnover Intention $=5.255$ (Constant) - (0.468 x Job Satisfaction - (0.068 x Organisational Commitment $\times$ Job Satisfaction $)+(0.248 \times$ Tenure of $6-10$ years)

\section{DISCUSSION}

Employee perceptions across the concerned constructs indicated that there was a positive sentiment towards both Organisational Commitment and Job Satisfaction within the organisation, while a neutral feeling emerged toward Turnover Intentions. This came to light as the Likert scale was utilised, where " 3 " was indicative of a neutral feeling. However, since the study's sampling was earlier described as convenient, only a once-off perceptions gauge was acquired. A further recommendation in this vein would be to suggest longitudinal studies. Studies of this nature would be of large value especially in terms of turnover intentions whereby the intentions may result in actual behaviour.

General consensus (as suggested earlier) indicates Organisational Commitment correlating more strongly to Turnover Intentions than does Job Satisfaction (Steel \& Ovalle, 1984). Mathieu and Zajac (1990) also established that, rather than Job Satisfaction, Organisational Commitment precedes Turnover Intentions. However, contrary to these expectations, this study determined that commitment does not correlate more strongly than satisfaction does with turnover intentions. This is in line with what Tett and Meyer (1993) discovered about Job Satisfaction and Organisational Commitment, contrary to popular belief. This indicates that withdrawal entails a rejection of the job rather than of the organisation. This may be due to the historic nature of the academic environment in which employees were given more job autonomy in their positions. However, of late administrative responsibilities and increasing requirements related to student output have changed what the job used to entail. Therefore, although the university has changed recently in terms of structure, change in job responsibilities has been continually changing - hence the greater impact of withdrawal cognitions.

Organisational commitment had a significant relationship with the age of the respondent where results indicated a trend emerging in which commitment to the organisation increases as age increases. This research supports the more recent findings of Cohen and Lowenberg (1990); Ingersoll et al. (2002); Kachmar and Carlson (1999); Lok and Crawford (1999); and Mathieu and Zajac (1990). These results have a rational basis given the nature of the institution, where job opportunities 'diminish' as staff become older and more specialised in their respective fields. 
A significant relationship was found between Organisational Commitment and the race of the respondent where it was seen that black respondents from the sample are more positive about the commitment to the organisation than the white respondents. This finding supports the findings of Vallabh and Donald (2001). South Africa is continually changing, weeding out the inequalities of the past, and therefore with the merger at hand, black staff will feel more committed to the changes than their white counterparts who may feel intimidated, particularly as historically, South African educational institutions were regarded as protected institutions.

Another significant relationship was also seen between Organisational Commitment and the highest academic qualification of the respondent, where it was found that Organisational Commitment decreased as the level of education increased. This finding supports the findings of several studies such as those of Cohen and Lowenberg (1990); Dornstein and Matalon (1989); Mathieu and Hamel (1989); and Mathieu and Zajac (1990). A higher academic qualification resulting in more job opportunities could be the rationalisation behind this result. Commitment may not be a psychological predisposition, but rather in this case the confidence one has about finding alternative work. Therefore the commitment to the organisation will be lowered as less 'dependence' is placed on the organisation.

Turnover Intentions had a significant relationship with the age of the respondent, as the results indicated that as age increased, intentions to stay are improved. This finding supports the research of Lambert et al. (2001). Research findings in this instance are not conclusive and contradictory. An older respondent does not necessarily equate to a more qualified one - hence the fact that this relationship holds value. Older respondents place more investment within an organisation, hence their intention to stay longer.

Furthermore, Turnover Intentions had a significant relationship with the tenure of the respondent as the results indicated that an inverted U-trend is encountered where Turnover Intentions increased initially as tenure increased, and then decreased once a peak is reached. The peak in this case is six to ten years. Jacobs (2005) and Lum et al. (1998) report similar findings. This may be due to the fact that the new employees are experiencing their twilight years while at the organisation and are also naïve about the organisation as a complete whole, while those who are very experienced are attached to the organisation after investing many years of service in it. Those in the six to tenyears category feel that they have experienced the organisation sufficiently and therefore feel a need to change.

An interaction relationship between race and gender was found (whereby the dependent variable was Turnover Intentions). It can be seen that white males and black females score higher (i.e. are more negative) than the black males and white females. This finding is also supported by Jacobs (2005). This is because black females (under government regulations) are very sought after in the workplace (more so than black males and white females) and this drives their Turnover Intentions into the negative. On the other side of the spectrum, white males were previously (and in some instances still are) the dominant role players in the workplace and this drive and focus are still maintained today, thereby reducing their intentions to stay.

Suggestions for further research highlight the need to incorporate other tertiary institutions (as well as other industries) in order to compare the results and to generalise a predictive model of the present study. Furthermore, by the inclusion of more internal and external variables, a more holistic picture would be possible and would add some insight into understanding the subjective experience of turnover intentions.
Bias analyses must be mandatory in all studies where there is access to the population data. While it is rarely carried out in most studies, it improves the validity of the research results. Addressing bias itself, a more proactive involvement is required when receiving the research results enabling the researcher to address those areas where it has been determined.

Turnover intentions of tertiary employees can be actively managed through the manipulation of the contextual variables of Organisational Commitment and Job Satisfaction. The resulting predictive model can be regarded as an important tool for management and the human resource department in effectively planning talent retention strategies focusing on the model's controllable dimensions. Since this model was developed on the basis of internal components, possible strategies could be derived from this model to prevent turnover intentions.

\section{REFERENCES}

Ajzen, I. (1991). The theory of planned behaviour. Organizational Behaviour and Human Decision Processes, 50(2), 179-211.

Armstrong-Stassen, M., Cameron, S.J., Mantler, J. \& Horsburgh, M.E. (2001). The impact of hospital amalgamation on the job attitudes of nurses. Canadian Journal of Administrative Sciences, 18(3), 149-162.

Arnolds, C.A. \& Boshoff, C. (2004). The management of the early stages of restructuring in a tertiary-education institution: An organisational commitment perspective. A South African Journal of Business Management, 35(2), 1-13.

Ashkenas, R.N. \& Francis, S.C. (2000). The fine art of friendly acquisition. Harvard Business Review, 78(6), 101-107.

Aven, F.F. Jr., Parker, B. \& McEvoy, G.M. (1993). Gender and attitudinal commitment to organizations: A meta-analysis. Journal of Managerial Issues, 11, 198-212.

Bainbridge, C. (1996). Designing for change: A practical guide to business transformation. Chichester, West Sussex: Wiley.

Bastien, D.T. (1987). Common patterns of behavior and communication in corporate mergers and acquisitions. Human Resource Management, 26(1), 17-33.

Becker, T.E. (1992). Foci and bases of commitment: Are they distinctions worth making? Academy of Management Journal, 35(1), 232-244.

Bedeian, A.G., Farris, G.R. \& Kacmar, K.M. (1992). Age, tenure, and job satisfaction: A tale of two perspectives. Journal of Vocational Behavior, 40, 33-48.

Bertz, R.D. Jr. \& Judge, T.A. (1994). Person-organisation fit and the theory of work adjustment: Implications for satisfaction, tenure, and career success. Journal of Vocational Behavior, 44, 32-54.

Brush, D.H., Moch, M.K. \& Pooyan, A. (1987). Individual demographic differences and job satisfaction. Journal of Occupational Behaviour, 8(2), 139-155.

Buono, A.F., Bowditch, J.L. \& Lewis, J.W. III (1985). When cultures collide. Human Relations, 38(5), 477-500.

Cano, J. \& Miller G. (1992). A gender analysis of job satisfaction, job satisfier factors, and job dissatisfier factors of agricultural education teachers. Journal of Agricultural Education, 33(3), $40-46$.

Cartwright, S. \& Cooper, C.L. (1990). The impact of mergers and acquisitions on people at work: Existing research and issues. British Journal of Management, 1, 65-76.

Chambers, J.M. (1999). The job satisfaction of managerial and executive women: Revisiting the assumptions. Journal of Education for Business, 75, 69-75.

Chiu, R.D. \& Francesco, A.M. (2003). Dispositional traits and turnover intention: Examining the mediating role of job satisfaction and affective commitment. International Journal of Manpower, 24(3), 284-298.

Clark, A., Oswald, A. \& Warr, P. (1996). Is job satisfaction U-shaped in age? Journal of Occupational and Organizational Psychology, 69, 57-81. 
Cohen, A. (1993). Organizational commitment and turnover: A meta-analysis. Academy of Management Journal, 36(5), 1140-1157.

Cohen, A. \& Lowenberg, G. (1990). A re-examination of the side-bet theory as applied to organizational commitment: A meta-analysis. Human Relations, 43(10), 1015-1050.

Cook, J.D., Hepworth, S.J., Wall, T.D. \& Warr, P.B. (1981). The experience of work. A compendium and review of 249 measures and their use. London: Academic Press.

Covin, T.J., Sightler, K.W., Kolenko, T.A. \& Tudor, R.K. (1996). An investigation of post-acquisition satisfaction with the merger. The Journal of Applied Behavioral Science, 32(2), $125-142$.

Davy, J.A., Kinicki, A., Kilroy, J. \& Scheck, C. (1988). After the merger: Dealing with people's uncertainty. Training and Development Journal, November, 57-61.

Dornstein, M. \& Matalon, Y. (1989). A comprehensive analysis of the predictors of organizational commitment: A study of voluntary army personnel in Israel. Journal of Vocational Behavior, 34, 192-203.

Fourie, M. (1999). Institutional transformation at South African universities: Implications for academic staff. Higher Education, 38, 275-290.

Fox, S.R. \& Fallon, B.J. (2003). Modeling the effect of work/life balance on job satisfaction and turnover intentions. Symposium paper presented at the 5th Australian Industrial and Organisational Psychology Conference, Melbourne, Australia.

Gersick, C.J.G. (1991). Revolutionary change theories: A multilevel exploration of the punctuated equilibrium paradigm. Academy of Management Review, 16, 10-36.

Green, M.F. \& Hayward, F.M. (1997). Transforming higher education: Views from leaders around the world. Phoenix: Oryx Press.

Greenhaus,J.H.,Parasuraman, S. \&Wormley, W.M. (1990). Effects of race on organisational experiences, job performance evaluations, and career outcomes. Academy of Management Journal, 33(1), 64-86.

Guimaraes, T. (1997). Assessing employee turnover intentions before/after TQM. International Journal of Quality \& Reliability Management, 14(1), 46-63.

Hackett, R.D., Bycio, P. \& Hausdorf, P.A. (1994). Further assessments of Meyer and Allen's (1991) three-component model of organizational commitment. Journal of Applied Psychology, 79(1), 15-23.

Hair, J.E., Black, W.C., Babin, B.J., Anderson, R.E. \& Tatham, R.L. (2006). Multivariate data analysis (6th edition). New Jersey: Pearson Prentice Hall.

Hellriegel, D. \& White, G.E. (1973). Turnover of professionals in public accounting: A comparative analysis. Personnel Psychology, 26, 239-249.

Herrera, R. (2003). Job satisfaction among athletic trainers in NCAA divisional institutions. The Sports Journal, 6(1), 1-7.

Herzberg, F. \& Mausner, B. (1959). The motivation to work. New York: Wiley.

Hom, P.W. \& Hulin, C.L. (1981). A competitive test of the prediction of reenlistment of several models. Journal of Applied Psychology, 66(1), 23-29.

Ingersoll, G.L., Olsan, T., Drew-Cates, J., De Vinney, B. \& Davies, J. (2002, May). Nurses' job satisfaction, organisational commitment, and career intent. Journal of Nursing Administration, 32(5), 250-263.

Jacobs, E.J. (2005). The development of a predictive model of turnover intentions of professional nurses. Unpublished doctoral thesis: University of Johannesburg.

Jansen, J.D. (2002). Mergers in higher education: Lessons learned in transitional contexts. Pretoria: University of South Africa.

Jones, J.M.S. (2000). The impact of hospital mergers on organizational culture, organizational commitment, professional commitment, job satisfaction, and intent to turnover on registered professional nurses on medical-surgical hospital units. Doctoral dissertation: State University of New York, Buffalo.
Kacmar, K.M. \& Carlson, D.S. (1999). Antecedents and consequences of organizational commitment: A comparison of two scales. Educational and Psychological Measurement, 59(6), 976-994.

Knoop, R. (1986). Job involvement: An elusive concept. Psychological Reports, 59, 451-456.

Lambert, E.G., Hogan, N.L. \& Barton, S.M. (2001). The impact of job satisfaction on turnover intent: A test of a structural measurement model using a national sample of workers. Social Science Journal, 38(2), 233-250.

Lee, K., Carswell, J.J. \& Allen, N.J. (2000). A meta-analytic review of occupational commitment: Relations with person- and work-related variables. Journal of Applied Psychology, 85(5), 799-811.

Lincoln, J.R. \& Kallenberg, A.L. (1990). Culture, control and commitment: A study of work organisation and work attitudes in the United States and Japan. Cambridge University Press: Cambridge.

Locke, E.A. (1976). The nature and causes of job satisfaction. M.D. Dunette (Ed.), Handbook of Industrial and Organizational Psychology (pp. 1297-1350). Chicago: Rand McNally.

Lok, P. \& Crawford, J. (1999). The relationship between commitment and organizational culture, subculture, leadership style and job satisfaction in organizational change and development. Leadership and Organization Development Journal, 20(7), 365-373.

Lubatkin, M. (1983). Mergers and performance of the acquired firm. Academy of Management Review, 8(2), 218-225.

Lum, L., Kervin, J., Clark, K., Reid, F. \& Sirola, W. (1998) Explaining nursing turnover intent: Job satisfaction, pay satisfaction, or organizational commitment. Journal of Organizational Behaviour, 19(3), 305-320.

Ma, C., Samuels, M.E. \& Alexander, J.W. (2003). Factors that influence nurses' job satisfaction. Journal of Nursing Administration, 33(5), 293-299.

Marsh, R.M. \& Mannari, H. (1977). Organizational commitment and turnover: A predictive study. Administrative Science Quarterly, 22, 57-75.

Maslow, A. (1943). A theory of human motivation. Psychological Review, 50, 370-396.

Maslow, A. (1954). Motivation and personality. New York: Harper and Row.

Mathieu, J.E. \& Hamel, K. (1989). A causal model of the antecedents of organizational commitment among professionals and nonprofessionals. Journal of Vocational Behaviour, 34, 299-317.

Mathieu, J.F. \& Zajac, D.M. (1990). A review and meta-analysis of the antecedents, correlates, and consequences of organizational commitment. Psychological Bulletin, 108(2), 171-194.

McFarlin, D.B. \& Sweeney, P.D. (1992). Distributive and procedural justice as predictors of satisfaction with personal and organizational outcomes. Academy of Management Journal, 35(3), 626-637.

Meyer, J.P., Stanley, D.J., Herscovitch, L. \& Topolnytsky, L. (2002). Affective, continuance, and normative commitment to the organization: A meta-analysis of antecedents, correlates, and consequences. Journal of Vocational Behavior, 61, 20-52.

Ministry of Education. (2001). National Plan for Higher Education. Pretoria: Ministry of Education.

Mobley, W.H. (1977). Intermediate linkages in the relationship between job satisfaction and employee turnover. Journal of Applied Psychology, 62(2), 237-240.

Mobley, W.H. (1982). Employee turnover: Causes, consequences and control. Michigan: Addison-Wesly.

Mobley, W.H., Griffeth, R.W., Hand, H.H. \& Meglino, B.M. (1979). Review and conceptual analysis of the employee turnover process. Psychological Bulletin, 36(3), 493-521.

Mobley, W.H., Horner, S.O. \& Hollingsworth, A.T. (1978). An evaluation of precursors of hospital employee turnover. Journal of Applied Psychology, 63(4), 408-414. 
Morrison, E.W. \& Robinson, S.L. (1997). When employees feel betrayed: A model of how psychological contract violation develops. Academy of Management Review, 22, 226-256.

Morrow, P.C. (1983). Concept redundancy in organizational research: the case of work commitment. Academy of Management Review, 8(3), 486-500.

Muchinsky, P.M. (1978). Age and job facet satisfaction: A conceptual reconsideration. Aging and Work, 1, 175-179.

Müller, S.M. \& Roodt, G. (1998). Die verband tussen werknemers se houding jeens regstellende aksie en hul werksbetrokkenheid: 'n Eksploratiewe studie [The relationship between employees' attitudes towards affirmative action and their work involvement: An explorative study]. SA Journal of Industrial Psychology, 24(1), 26-32.

Naudé, J.L.P. \& Rothman, S. (2004). Burnout of emergency workers in South Africa. Paper presented at the Second South African Work Wellness Conference, Potchefstroom, South Africa, 26 March 2004

Newman, J.E. (1974). Predicting absenteeism and turnover: A field comparison of Fishbein's model and traditional job attitude measures. Journal of Applied Psychology, 59(5), 610- 615.

Oswald, A. (2002). Are you happy at work? Job satisfaction and work-life balance in the US and Europe. Retrieved November 17, 2006, from www.andrewoswald.com

Oswald, A. \& Gardner, J. (2001). What has been happening to job satisfaction in Britain? Retrieved November 17, 2006, from www.warwick.ac/soc/economics/staff

Porter, I.W., Steers, R.M., Mowday, R.T. \& Boulian, P.V. (1974). Organizational commitment, job satisfaction, and turnover among psychiatric technicians. Journal of Applied Psychology, 59(5), 603-609.

Price, J.L. \& Mueller, C.W. (1981). Professional turnover: The case for nurses. Ames: Iowa State University Press.

Reddy, J. (1998). Regional consortia, partnerships, mergers and their implications for transformation of the South African higher education system. Johannesburg: USAID.

Reilly, N.P. \& Orsak, C.L. (1991). A career stage analysis of career and organizational commitment in nursing. Journal of Vocational Behavior, 39, 311-330.

Roodt, G. (1992). Organisasieklimaat as voorspeller van organisasieverbondenheid: Getuienis van 'n suiwer kognitiewe definisie? [Organisation climate as predictor of organisational commitment: Evidence of a pure cognitive definition?] Acta Academica, 24(4), 109-122.

Roodt, G. (1997). Theoretical and empirical linkages between work-related commitment foci. SA Journal of Industrial Psychology, 23(2), 6-13.

Roodt, G. (2004a). Concept redundancy and contamination in employee commitment research: Current problems and future directions. SA Journal of Industrial Psychology, 30(1), $82-90$.

Roodt, G. (2004b). Turnover intentions. Unpublished document: University of Johannesburg.

Rosenthal, R., Rosnow, R.L. \& Rubin, D.B. (2000). Contrasts and effect sizes in behavioural research: A correlational approach. Cambridge: Cambridge University Press.
Sager, J.K., Griffeth, R.W. \& Hom, P.W. (1998). A comparison of structural models representing turnover cognitions. Journal of Vocational Behaviour, 53(2), 254-273.

Shields, M.A. \& Ward, M. (2001). Improving nurse retention in the National Health Service in England: The impact of job satisfaction on intentions to quit. Journal of Health Economics, 20(5), 677-701.

Shore, L.M., Newton, L.A. \& Thornton, G.C. (1990). Job and organizational attitudes in relation to employee behavioural intentions. Journal of Organizational Behaviour, 11(1), 57-67.

Singh, D. (1999). Attitude toward an acquisition and organizational commitment, and intention to quit. Master's thesis: San Jose State University.

Slate, R.N. \& Vogel, R.E. (1997). Participative management and correctional personnel: A study of the perceived atmosphere for participation in correctional decision making and its impact on employee stress and thoughts about quitting. Journal of Criminal Justice, 25(5), 397-408.

South Africa. (1997). Higher Education Act, No. 101 of 1997. Pretoria: Government Printer.

Spector, P.E. (1997). Job satisfaction: Application, assessment, causes, and consequences. London: Sage Publications.

SPSS Inc. (2005). AMOS 6.0 User's Guide. Chicago: SPSS, Illinois.

Steel, R.P. \& Ovalle, N.K. (1984). A review and meta-analysis of research on the relationship between behavioural intentions and employee turnover. Journal of Applied Psychology, 69, 673-686.

Tett, R.P. \& Meyer, J.P. (1993). Job satisfaction, organizational commitment, turnover intentions, and turnover: Path analyses based on meta-analytic findings. Personnel Psychology, 46, 259-293.

Tuch, S.A. \& Martin, J.K. (1991). Race in the workplace: Black/ white differences in the sources of job satisfaction. The Sociological Quarterly, 32, 103-116.

Vallabh, M. \& Donald, F. (2001). A comparison of black and white managers on intent to leave and job mobility. SA Journal of Industrial Psychology, 27(2), 37-42.

Vergani, L. (1999, March). South Africa's black universities struggle to survive in a new era. The Chronicle of Higher Education, 45(27), A45-A46.

Weber, Y., Lubatkin, M. \& Schweiger, D. M. (1994). Top management turnover following mergers: A longitudinal study of perceptual and attitudinal determinants. Annual Meeting of Academy of Management, Dallas, TX.

Weiss, D.J., Dawis, R.V., England, G.W. \& Lofquist, L.H. (1967). Manual for Minnesota Satisfaction Questionnaire. Minneapolis: University of Minnesota.

Witt, L.A. \& Nye, L.G. (1992). Gender and the relationship between perceived fairness of pay or promotion and job satisfaction. Journal of Applied Psychology, 77(6), 910-917.

Yin, J.T. \& Yang, K.A. (2002). Nursing turnover in Taiwan: A meta-analysis of related factors. International Journal of Nursing, 39(6), 573-581.

Zhu, Y., May S.K. \& Rosenfield, L.B. (2004). Information adequacy and job satisfaction during merger and acquisition. Management Communication Quarterly, 18(2), 241-270. 